\title{
Investigation of Optimum Crew Transfer Vessel Fleet for Offshore Wind Farm Maintenance Operations
}

\author{
Yalcin Dalgic, Iraklis Lazakis and Osman Turan \\ Department of Naval Architecture, Ocean and Marine Engineering, \\ University of Strathclyde, Glasgow, G4 OLZ, UK
}

Received 10/05/20I4; Accepted 03/10/2014

\begin{abstract}
The offshore wind industry, which aims to reduce the operational costs, usually achieved through learning curves and supply chain improvements, has seen drastic cost increase over the last five years. In order to sustain the competitiveness of the offshore wind industry against other renewable energy sources, the cost of offshore wind needs to come down to today's onshore cost. This cost reduction target can be achieved through optimising the offshore related operations which contribute the most to the operating expenditures (OPEX) of the offshore wind farms. In this paper, the investigation of optimum crew transfer vessel fleet, which indicates the influence of fleet size and characteristics of the vessels involved in the operations, is introduced with a focus on power production, total cost of the Operation and Maintenance (O\&M) and revenue loss. A time domain Monte-Carlo approach is adopted while taking into consideration the climate parameters, failure characteristics of turbine components, the specification of crew transfer vessels, and the composition of vessel fleet. Through this extensive study, it is concluded the 0\&M related costs can be reduced significantly while the availability and the productivity of the turbines can be increased by optimising the use of the 0\&M vessel fleet in terms of fleet size and vessel capabilities.
\end{abstract}

Keywords: Offshore Wind, Operation and Maintenance, Crew Transfer Vessel, Fleet Optimisation, Accessibility, Operability

\section{INTRODUCTION}

Over the last few years, developers/operators were encouraged to invest in offshore wind energy due to larger areas which could accommodate major offshore projects, absence of limitations associated with visual impact and noise, higher wind potentials, and lower turbulence levels in the offshore environment. Despite all these advantages, electricity generation from offshore wind is still considerably more expensive compared to onshore wind [1]. In order to decrease the cost of electricity generation and increase the competitiveness of the offshore wind industry against other alternative energy sectors, it is essential to minimise the Operation and Maintenance (O\&M) costs. In this respect, vessels are particularly important, since the costs for vessels account for $50 \%$ of the total O\&M costs [2-5]. Due to the fact that each turbine typically requires approximately six visits per year mainly for minor O\&M activities [6]; number of Crew Transfer Vessels (CTVs) account for $40.6 \%$ of the market, while cabling vessels, jack-up vessels, heavy lift vessels and other vessel account for $21.3 \%, 16 \%, 12 \%$, and $10 \%$, respectively [7].

*Corresponding Author: Yalcin Dalgic

Tel: +44 (0)141548 4778,+44 (0)141548 4094 Fax: +44 (0)141 5522879

E-mail Addresses: yalcin.dalgic@strath.ac.uk,iraklis.lazakis@strath.ac.uk,o.turan@strath.ac.uk

Postal Address: Department of Naval Architecture, Ocean and Marine Engineering, University of Strathclyde, 100

Montrose Street, Glasgow G4 OLZ, United Kingdom 
Although the majority of the projects are still in the warranty period, in less than five years $79 \%$ of wind turbines are set to move out of warranty [8]. Furthermore, current offshore access systems allow access for 200 days of the year, which may decrease significantly due to harsher conditions in further offshore fields. Therefore, operators have to plan the O\&M activities and associated costs in depth, as they will have to bear these costs in the near future.

Therefore, the main focus of this paper is to optimise CTV fleet towards optimum O\&M cost, minimum revenue loss, and maximum electricity generation while analyses of environmental conditions, investigation of failure rates, and assessment of vessel operations form the foundations of this study. Using the results of this study, it will be possible to decide the specifications of CTVs and the composition of the fleet which will bring the most economical benefits. The paper is structured as follows; in section 2, the common procedures, aspects and issues associated with the maintenance of offshore wind farms are presented. Through the observations in that section, the proposed methodology is explained in section 3. A case study is presented in section 4 in order to validate the proposed model. The results of the study are demonstrated in section 5 while concluding remarks are presented in the concluding section.

\section{LITERATURE REVIEW}

Currently, offshore wind O\&M related research is dominated by the preventive and predictive maintenance concepts. Whilst preventive maintenance related research is interested in the optimisation of O\&M intervals [9-14], predictive maintenance related research intended to improve the performance of condition monitoring systems [15-17] and evaluate the reliability performances of different components and compositions [18-20]. However, these models are still not complete enough to provide sufficient support for offshore wind due to the fact that vessel specific attributes are generally neglected or ignored. Furthermore, the implementation of these maintenance approaches does not give satisfactory results for the entire offshore wind farm projects.

\section{I. CTV selection}

There are several attributes which have to be considered in the CTV selection process. Figure 1 presents the majority of these attributes in a single framework. Vessel specification, financial

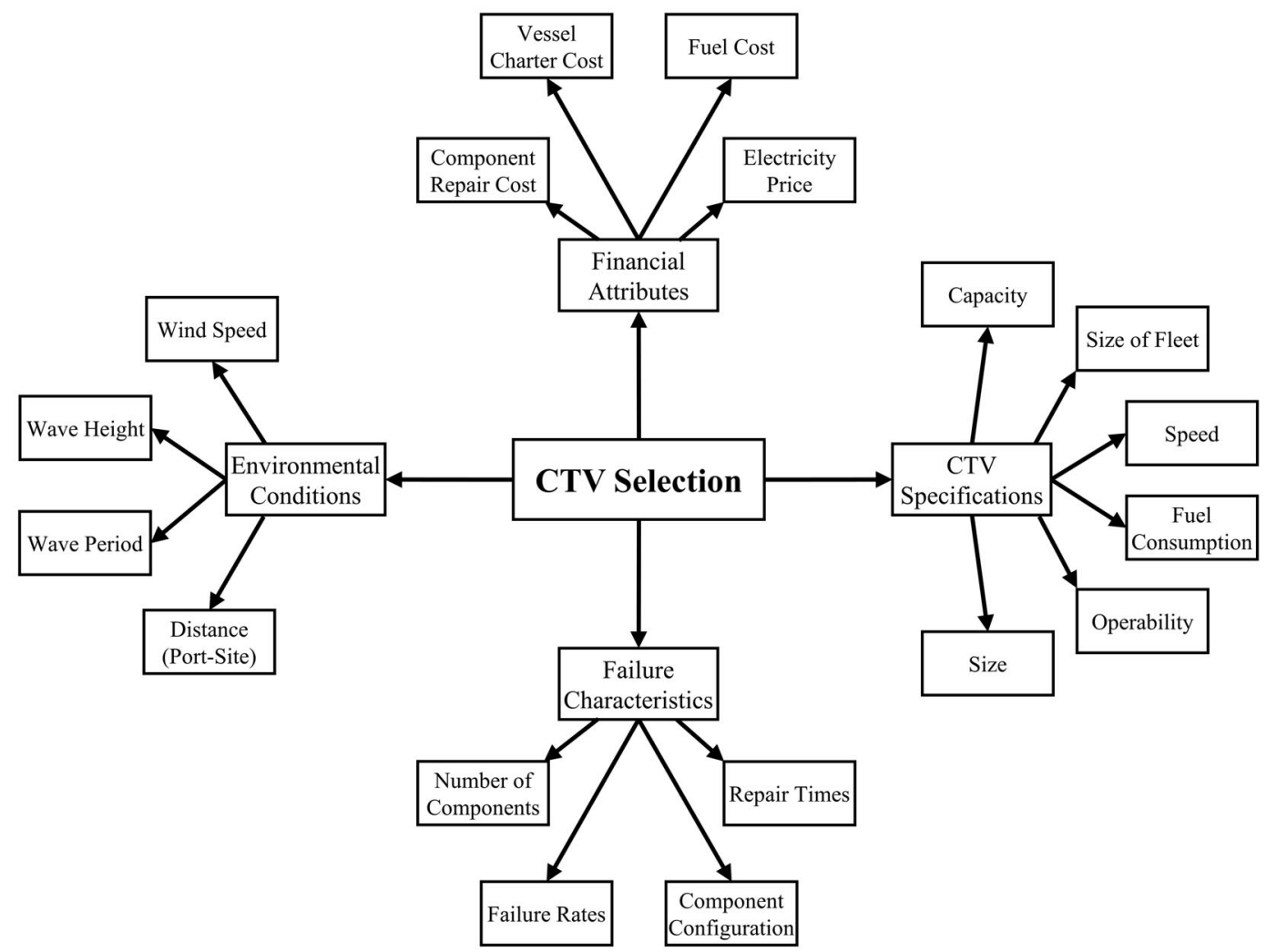

Figure I. Attributes in the CTV selection process 
attributes, environmental conditions, and failure characteristics are the major segments in the CTV selection process. There are also several sub-sections related to each segment. It has to be highlighted that the number of segments and sub-sections can vary depending on the scope of the analyses.

\section{I.I. CTV Specifications}

One of the main issues in the O\&M planning is the disregard of vessels and their influence on the maintenance methodology. It is not possible to represent offshore O\&M activities without considering the environmental factors and the influence of these factors on the vessel operations. As explained in the previous sections, O\&M activities cannot be performed without offshore access, and thus, it is necessary to consider vessel specific attributes and reaction time to the failures in the maintenance methodology.

Monohull boats, small catamaran vessels, and small water-plane area twin hull (SWATH) vessels are generally utilised in minor maintenance operations, which allow operators to keep the cost of minor maintenance operations at optimum level. Benefits and drawbacks of these vessels are listed in Table 1. Catamaran configurations are often the preferred choice by the operators [21]. The most distinctive characteristics of these vessels are high speed, small deck spaces, small crane capacities and safe access to wind turbine structures that will allow operators to take quick actions in the case of unexpected failures.

\section{I.2. Financial Attributes}

Financial attributes include the costs and the loss of revenue that influence the CTV fleet selection. The vessel fuel cost, electricity selling price, CTV daily charter rates, and the actual repair cost of the components comprise the financial attributes group of the decision process. As in other industries, all the economic decisions are based on trade-offs between risk and cost. The most costefficient decisions are associated with the biggest risks. Conversely, the safest decisions require the highest investments/costs. Neither of these options are acceptable for the offshore wind farm operators due to the huge financial size of the projects and due to the cost of maintenance operations.

For instance, if an operator makes a risky decision and selects a vessel with the lowest characteristics which can reduce the vessel associated costs, then the lost revenue may reach extreme points due to very low accessibility during the lifecycle of the project. On the other hand, if an operator makes a safe decision and selects a vessel with highest characteristics which can provide sufficient support for O\&M, but this situation may lead to a significant increase in the charter and fuel costs.

Table I. Different CTV characteristics

\begin{tabular}{lll}
\hline Vessel type & Benefits & Drawbacks \\
\hline Monohull & - Very high speed $(\sim 30$ knots $)$ & - Limited passenger $(6$ to 8$)$ \\
& - Reasonably lower charter rates & - Limited cargo capacity \\
& - Lower fuel consumption & - Uncomfortable for passengers, \\
- & High availability in the & no other facilities available \\
& offshore market & - Limited safe access to turbines $\left(\mathrm{H}_{S}<1 \mathrm{~m}\right)$ \\
Catamaran & - High speed $(\sim 20$ knots $)$ & - Limited passenger $(12$ and more $)$ \\
- & Operational $\mathrm{H}_{s}=1.5 \mathrm{~m}$ & and cargo capacity \\
& - Safe access to turbines & - Limited cargo capacity \\
SWATH & $\left(\mathrm{H}_{S}<1.2 \mathrm{~m}\right)$ & - Relatively higher charter rates \\
- & - Capacity of 12 to $60 \mathrm{passengers}$ & - Limited cargo capacity \\
- & High speed $(\sim 20$ knots $)$ & - Low availability in the offshore \\
- & Operational $\mathrm{H}_{s}=2.0 \mathrm{~m}$ & wind market \\
- & Safe access to turbines & - Relatively higher charter rates \\
& $\left(\mathrm{H}_{S}<1.5 \mathrm{~m}\right)$ & \\
- & Comfortable for passengers & \\
\hline
\end{tabular}


The decision process related to fleet size is also important. Lower vessel numbers may lead to cost reductions in the vessel associated O\&M costs, while on the other hand wind turbine failures may remain unrepaired due to lack of resources, which increase the downtimes and the unavailability. The alternative option would create redundancy which is not acceptable, especially when the main target is to decrease the cost of maintenance operations. Therefore, it is not enough to decide the type, size, etc. of the CTV; the decision process has to be supported by the choice of the number of CTVs which will be used in the O\&M fleet.

\section{I.3. Environmental Conditions}

Environmental conditions are another important measure which influence the O\&M activities. Wind speed, wave height and wave period are major environmental constraints which will not only affect the journey specific issues, but also the electricity generation of the offshore wind farms. In a generic content, areas with stronger wind characteristics are more valuable for electricity generation. However, with regard to O\&M, stronger wind is a constraint, similar to higher wave heights with shorter wave periods. Furthermore, stronger wind speeds have a negative effect on the failure characteristics of the wind turbine components [22].

\section{I.4. Failure Characteristics}

Two main approaches are established in the failure characteristic and reliability investigation of offshore wind turbines. Whilst some of the studies investigated only a limited number of components or a single system in detail; such as generator system, grid connection, transmission [23-26]; other studies focused on the entire wind farm composition [27, 28], but missed some critical issues. Utne [29] discussed the maintenance strategies for deep-sea offshore wind farms and also indicated that the existing models consider single units and single component systems. Although these research studies considered theoretical solutions related to the reliability issues, none of them represent the real operational offshore environment. There are many theoretical models, however most of them are not applicable to the offshore wind industry [29]. El-Thalji [30] indicated that it is critical to utilise models and techniques, which should be suitable for the real life application/scenarios in the actual operating environment.

\section{METHODOLOGY}

It is intended to synthesise and simulate five main calculation/analyses blocks in the proposed CTV fleet selection methodology; climate data generation block, failure analysis block, vessel transit model block, power calculation block and finally cost calculation block (Figure 2). In climate data

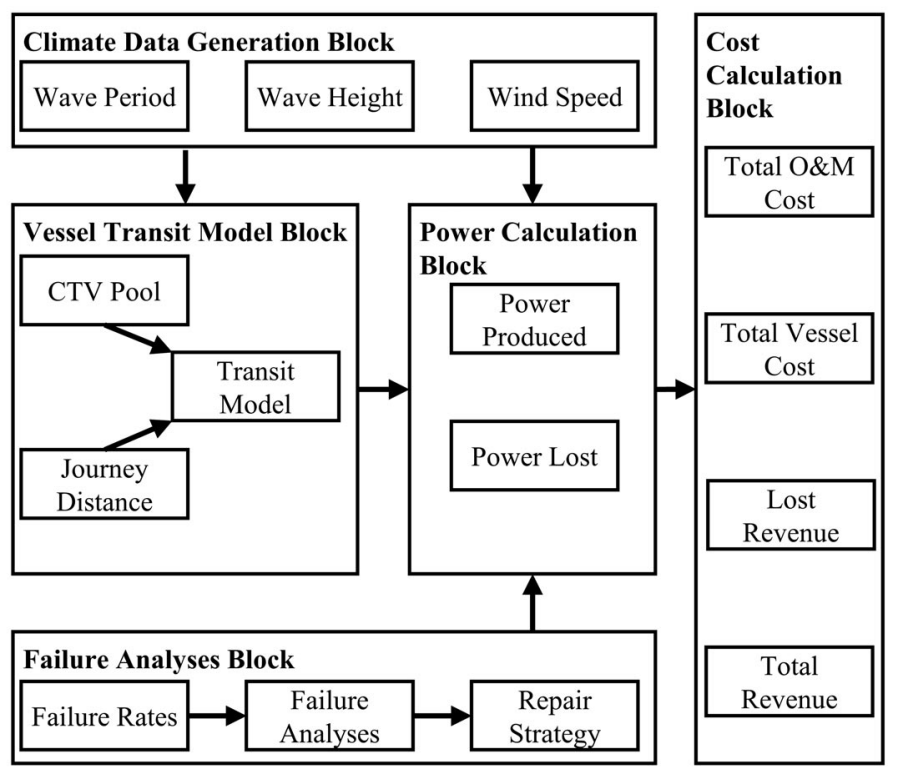

Figure 2. Proposed methodology 
generation block wind speed, wave height and wave period datasets are created to provide information for other blocks. Whilst all the generated datasets provide information for the transit model, wind speed dataset also provides inputs for the power calculation block. Time dependent failure rates are analysed within failure analysis block from which mean time between failures (MTBF) and mean time to repair (MTTR) values are provided to the power calculation block. In the vessel transit model block, journey specific calculations are performed for different CTVs in the vessel pool whilst total power produced and power lost due to failures, delays, and O\&M activities are calculated in power calculation block. Cost calculation block is the final section where all the information from previous blocks is collected and outputs are generated to support the optimisation of CTV fleet for offshore wind farms.

\section{I. Climate data generation block}

Generally the climate datasets are not sufficient to cover the entire lifecycle of offshore wind farms. Although the data may cover the past 20-25 years, it is rare that the climate data will present exactly the same track in the following 20-25 years. On the other hand, it is important to generate a dataset with the same characteristics of the original dataset. In this respect, the original dataset, which includes wind speed, wave height, and wave period observations are divided into multiple yearly datasets, number of which is defined by the duration of the original dataset, $L_{\text {org }}$ (years). All the divided datasets consist of wind speed, wave height, and wave period observations within a period of 1 year. Wind speed, wave height, and wave period observations are not disjointed from each other in order to preserve the correlation.

After dividing the original dataset into number of multiple yearly datasets $\left(L_{\text {org }}\right)$, a discrete uniform distribution that defines equal weights on the integers from 1 to $L_{\text {org }}$, is utilised for random sampling process. In this respect, each integer represents one of the pre-divided datasets; thus the selection of an integer indicates the selection of a pre-divided dataset which is represented by that integer. Random sampling continues until the number of randomly selected integers become equal to the length of simulations, $L_{\text {sim }}$ (years). The sampling procedure involves choosing random samples with replacement which means that every sample is returned to the dataset after sampling. So a particular integer from the original dataset could appear multiple times.

Commonly, wind speed data is collected from a single location (height) of the observation centres. However, the maintenance operations are performed at different altitudes (sea level and hub level). Therefore, the wind speed data, which is related to a single height, has to be transformed into wind speeds at different altitudes so as to enhance the precision of the proposed model.

Various methods [31-33] exist related to the extrapolation of wind speed to the hub height of the wind. Among these methods, the Wind Power Law is the most widely used method [34], which is presented in Eqn 1;

$$
v_{2} / v_{1}=\left(h_{2} / h_{1}\right)^{\alpha}
$$

where $v_{2}$ is wind speed at elevation $h_{2}, v_{1}$ is wind speed at reference height $h_{1}$. The shear exponent $\alpha$ is not a constant value; it varies depending on atmospheric conditions, temperature, pressure, humidity, time of the day and nature of terrain [35]. In offshore environment, the shear component can typically be assumed to be equal to $0.1[36,37]$.

\subsection{Transit model block}

In order to calculate the influence of different attributes for the CTV selection and the costs associated with them, it is important to perform transit time calculations in a comprehensive manner. Despite the fact that existing O\&M models did not consider the effect of transit time on the O\&M, it is believed that environmental conditions cause significant delays for the journeys.

In this respect, the transit model block will be formed in order to calculate 'travel time', 'idle time', and 'working time' for each day of the simulations by considering that each time-step will have different climate characteristics (different wind speed, wave height, and wave period). 'Travel time' is the time spent on the journey (incoming and outgoing), 'working time' is the time spent for the actual O\&M activity, and 'idle time' is the period when CTVs are kept in the port due to weather restrictions.

The total distance between the loading port and the offshore wind farm is the constant input for the transit time calculations. The variations on the vessel speed due to environmental effects 
create fluctuations in the transit time calculations. Therefore, it is important to calculate the speed of the vessel accurately in each time-step. The model calculates the transit time by calculating the individual distances that are logged by the vessel in each time-step (Eqn 2). When the summation of individual distances becomes equal to the total distance between the loading port and the offshore wind farm, the model assumes that the vessel reached the offshore wind farm (Eqn 3).

$$
\begin{gathered}
\text { Distance }_{i}=\text { Time step interval } \times V_{i} \\
\text { Total Distance }=\sum_{0}^{i} \text { Distance }_{i}
\end{gathered}
$$

In order to verify the CTV speed $\mathrm{V}_{i}$ in each time-step; resistance and power analyses are performed for each individual CTVs in the vessel pool under different environmental conditions. The steps below are followed in the CTV speed calculations;

1. Calculation of total efficiency and calm water resistance of each CTV in the vessel pool: The most accurate method to calculate the total efficiency and the calm water resistance $\left(R_{\text {TCalm }}\right)$ of the CTV is model testing in a towing tank and scaling up the results to ship scale; alternative formulations which are presented by Helm [38] and Moody [39], can also be utilised. However, these equations are valid assuming the ship is sailing in calm water which is not always the case in the operational environment. When sailing in heavy seas, the vessel is subject to the added wave resistance and therefore the propeller can be running up to $7-8 \%$ heavier than in calm water. Besides the sea margin, $10-15 \%$ of engine margin is frequently added as an operational margin for the engine [40].

2. Calculation of added resistance $\left(R_{A W i}\right)$ and total resistance $\left(R_{T i}\right)$ : The experimental curves of the non-dimensional added resistant coefficient $\sigma_{A W}$ which are plotted against wave frequency $\omega$ can be found in [41]. Due to the fact that wave frequency varies between each time step, it is necessary to perform added resistance calculations for all the time steps. The total resistance of the CTV at ith time step can be calculated by using eqn 4

$$
R_{T_{i}}=R_{A W_{i}}+R_{T_{\text {Calm }}}
$$

3. Calculation of speed losses and achievable speeds for each time speed in waves: Whilst a CTV is traveling in waves, the skipper can keep the power constant and decrease the speed or keep the speed constant and increase the power. In the transit model block, the power and thrust of the CTVs will be kept constant and speed will change with the influence of waves. In this respect, the speed loss and the achievable speed by the CTV in each time step under the condition of constant power and thrust can be calculated by the formulations in Berlekom, et al. [42] and Berlekom [43].

4. Calculation of transit time: The calculation of distance which CTV travels in each time step interval can be calculated by Eqn 5

$$
\text { Distance }_{i}=\text { Time Step Interval } \times V_{a i}
$$

\subsection{Constraints in the Transit Model Block}

Maximum operational wind speed and maximum operational wave height values for CTVs will be the main constraints of the transit model block. When the generated climate values exceed these predefined values, the vessel speed at this time step will be set to zero, which indicates that the CTVs cannot sail under these environmental conditions. One additional point is that the environmental conditions may allow O\&M operations several times for a limited time in the same day, for instance 2 hours in the morning, 5 hours in the afternoon. In this case, the model considers the maximum weather window in that shift and allocates the CTVs in this period. It is considered that between departure and arrival of the CTVs, the environmental conditions will be sufficient enough for sailing without any interruption.

In addition to the environmental constraints, there might be circumstances which the distance that is logged in sequential time steps might not be sufficient enough to make the journey 
cost-effective. Additionally, there might be some cases that the time spent on the journey might be longer than the time spent on the actual O\&M activity. Therefore, a 'minimum working limit' has to be defined for making a working shift acceptable and cost-effective. The 'minimum working limit' will create extra constraint for the transit model. Although, maximum weather window value is more than the summation of the 'working time' and the 'travel time'; if the 'working time' value for that day is less than the 'minimum working limit', 'working time' and the 'travel time' values will be set to zero and 'idle time' will be set to the period shift, which indicates that the CTVs will not sail during this day, because the cost of the journey will be higher than the benefits that will be gained from the O\&M activity.

\subsection{Failure analyses block}

A time domain Monte-Carlo approach has been adopted, which relies on random number generation to ensure that all possibilities are covered in an unbiased manner. Such an approach requires deterministic and stochastic events. While the former is governed by the inputs and the assumptions; turbine failures and weather conditions comprise the stochastic elements of the simulation. During simulation each operational turbine is given the chance to fail at each time step. At this point, the model cycles through the simulation schedule in a randomised order. For each time step a random number between 0 and 1 is generated from a uniform distribution.

The performance of each component $i$ can be represented by a binary indicator variable $x_{i}$ where

$$
x_{i}= \begin{cases}\frac{1,}{0,} & \text { if component is functioning } \\ 0, & \text { if component has failed }\end{cases}
$$

for $i=1,2, \ldots, n$, where $n$ is the number of components in the system. Similarly, a binary variable $\varnothing$ denotes the state of the system.

$$
\varnothing_{\mathrm{i}}= \begin{cases}\frac{1,}{0,} & \text { if system is functioning } \\ 0, & \text { if system has failed }\end{cases}
$$

The reliability $R$, failure density $f$ and time dependent failure rate $\lambda$ of a system at time $t$ are

$$
\begin{gathered}
R(t)=e^{-\int_{0}^{t} \lambda(\mathrm{t}) \mathrm{dt}} \\
f(t)=-d R(t) / d t \\
\lambda(t)=-\frac{1}{R(\mathrm{t})} \frac{d R(t)}{d t}
\end{gathered}
$$

In a series system, the system can function if and only if all components are in the functioning state. Otherwise, the entire system fails. The series system does not imply physical series connections of electrical or mechanical components. It refers to how such product failure depends on component failure. The reliability of a series system $R_{s}$ at time $t$ is

$$
R_{s}(t)=\prod_{i=1}^{n} e^{-\lambda_{i} t}
$$

In a parallel system, the system fails if all components fail or the system performs satisfactorily if at least one of the $n$ components performs satisfactorily which is also called redundancy. The reliability of a parallel system $R_{p}$ at time $t$ is

$$
R_{p}(t)=1-\prod_{i=1}^{m}\left(1-R_{i}\right)
$$

\subsection{Failure Rate Progress}

At the beginning of a simulation, time steps of the first failures and the components that are failed for each turbine are identified. After this stage, the analyses are continued separately for each turbine. A CTV is allocated for the turbine which is failed first and the repair is performed. The details related to repair strategy and CTV allocation will be given in the following sections. When the failure is repaired and the time step at which the turbine starts functioning again is identified, 
the failure rate of the failed component is reset to the beginning level, as the repaired component is assumed 'as good as new' condition. Due to the fact that other components are remained untouched within the repair period, the failure distributions of those components are shifted forward to the time step which the turbine starts to function. Thus, the failure distributions of these components continue from the level at which the failure has occurred; however the distribution of the failed component is reset which requires an update on the system failure distribution regardless of whether the system is parallel or series.

In this respect, the failure distributions of the components and the system are updated and a new Monte-Carlo simulation is run from the time step at which the turbine starts to function until the end of the simulation period through using the updated failure distribution of the system. As a result of the new simulation, the subsequent failure of the turbine is identified. If there is no subsequent failure for that specific turbine or the time is not enough to repair the failure within the simulation period, the following failure type of that specific turbine is set to infinity (INF).

If there are multiple turbine failures on the same day of the simulations, those failures are simulated separately. The simulations continue until all the subsequent failure types for all turbines are set to INF which is generally at the very end of the simulation period. The definition of all the following failure types to INF indicates that either any new failure will not occur after that specific time step or the current failures cannot be repaired which also means that a failure cannot occur because the situation of the turbine will not change from failed state to functioning state.

\subsubsection{Repair Strategy}

The main concept of the repair strategy is, whilst examining the reliability at the component level, to structure the O\&M activities at the wind farm level. Therefore, the characteristics of individual wind turbine components will play a key role in the reliability analyses; however final O\&M decisions will be made by considering the offshore wind farm as a single unit.

When a failure occurs, the turbine is shut down and a crew, if available, is allocated to perform the repair. If all crews are either occupied with repair operations or are not on duty, the turbine will remain down, and a crew will not be assigned until a team becomes available to work. When a crew becomes available and is assigned to conduct the repair work, that crew can only be deployed to the failed turbine if the current weather conditions are within the turbine access limits as defined in the model inputs. If these conditions are not met, the crew remains at the base and are only dispatched to the assigned turbine once the weather improves to within the access limits.

The time taken to repair the turbine, once the crew are in attendance, is determined by repair time value specified for the failure. The model keeps track of the remaining repair time as the work progresses. Once the repair is completed, the turbine is restarted. If during repair, weather conditions worsen to a level beyond the specified turbine access limits; repair operations are suspended and the crew returns to base. In this instance, the turbine concerned remains inoperative. However, the work which is already performed is logged, thus the remaining repair can be completed in the following accessible day.

Scheduled maintenance is implemented by the crew members within the specified service interval. Repair work takes precedence over scheduled maintenance, which is suspended if the crews are required for repairs. If there is sufficient time to do scheduled maintenance after the repair work, the crew stays in the wind turbine and continues with the scheduled maintenance. Like the repair works, scheduled maintenance is also logged for each individual turbine.

\subsubsection{CTV and Technician Allocation}

Depending on the environmental conditions on the repair day and the capabilities of the CTVs in the vessel pool, more than one CTV can be available for the corrective maintenance task. In this case, there are number of priority checks which are illustrated in Figure 3. Theoretically, one CTV can operate for an unlimited number of turbines in a single shift, however this situation does not represent reality; therefore a value is defined for limiting the number of visits that can be done by one CTV in a single shift. As in the number of visits for CTVs, theoretically the allocation of more technicians will lead to the completion of the repair in a shorter time period, however in reality there is a maximum value, above which an increase in the number of technicians will not bring an 


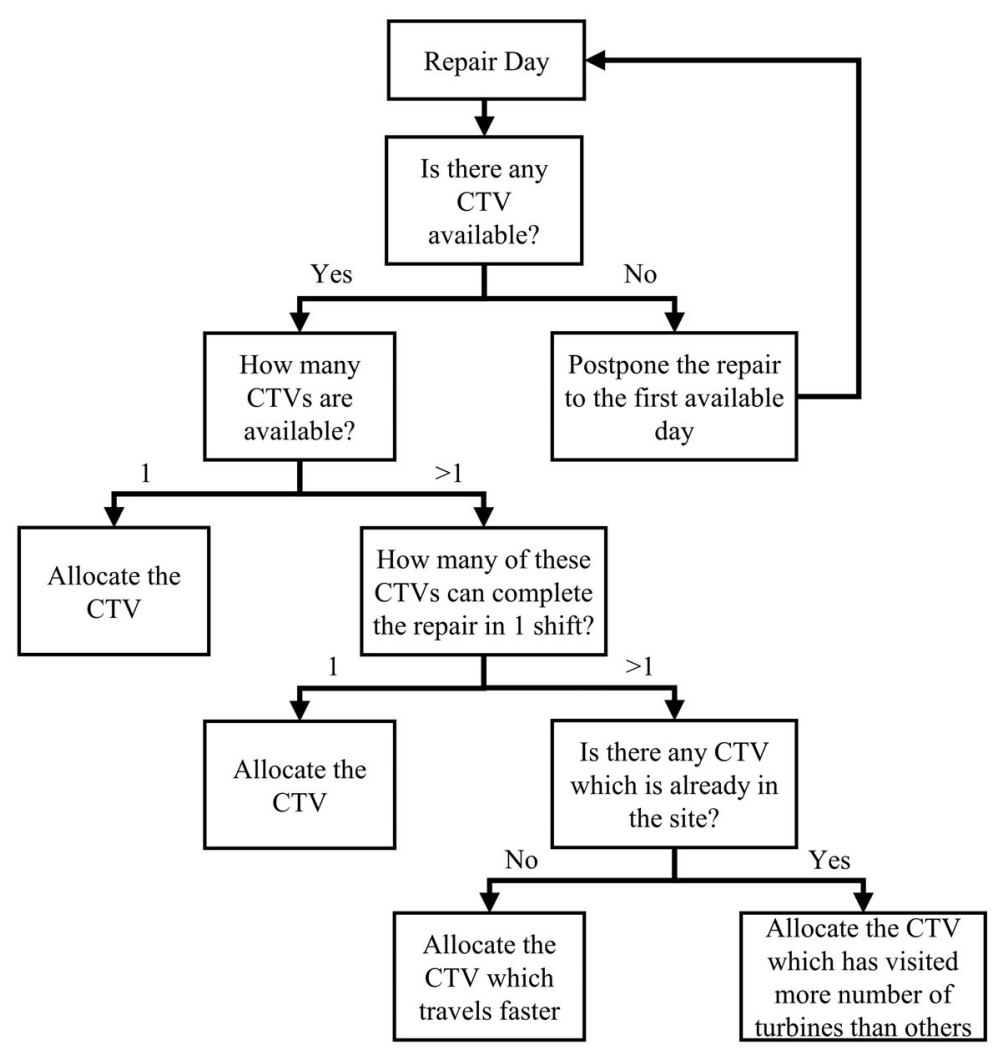

Figure 3. CTV allocation

advantage on the repair time. Therefore, two values are defined in order to represent the number of technicians that will be allocated in two conditions,

- minimum number of technicians that will be allocated in normal repair conditions

- maximum number of technicians that will be allocated in order to reduce the repair time and/or complete the repair in a single shift

The maximum number of technicians will be allocated unless the repair can be completed in a single shift by the minimum number of technicians. If the repair task cannot be completed even by the maximum number of technicians in a single shift, these technicians will be allocated to that repair task in the following repair days until the repair task is completed.

\subsection{Power calculation block}

The power calculation block will be driven by the climate data generation block and the failure analyses block. Climate will influence the power production levels of wind turbines related to how high the wind speed is and repair strategy will affect the time steps that the turbines are in functional or failed state. The outcome of the power generation block is the power produced in each time step and the total generation of wind farm within the simulation period.

\subsection{Cost calculation block}

With regard to cost attributes for CTVs, fuel cost, technician cost and charter cost is calculated within the analyses period and will be reflected on the total vessel cost and total O\&M cost values. The cost attributes are calculated individually for each fleet composition in each simulation and averaged when the simulations are completed. Daily charter rates of the vessels, technician salaries, repair cost of components, fuel cost, and electricity selling price are cost elements which will be considered in the simulations. In addition different inflation rates can be defined for each cost attribute, considering the fact that component prices may go down due to technological development, on the other hand staffing cost may go up due to increase in the demand for crews. 
Whilst the charter costs and the daily costs of technicians will be calculated for the entire analyses period, regardless of the value of 'travel time' and 'working time', fuel costs will be calculated depending on the summation of 'travel time' for each day. It is important to highlight that the charter cost is paid to the vessel owner continuously, even though the utilisation level of the vessel is low. On the contrary, fuel cost is dependent on the distance and the number of O\&M operations.

\section{CASE STUDY}

To evaluate the accuracy of the proposed model, a case study is performed. In the simulations, the fleet compositions which are formed from 2 different CTVs are ranked. The fleet size which varies from 1 to 10 is evaluated in the calculations. In addition, 3 different operational wave height limits are investigated for each CTV in order to assess the influence of operational capabilities of the CTVs. 100 simulations are run for each 65 different fleet compositions in order to cover different variations in the results due to the randomisation of variables in the Monte-Carlo simulation process.

Table 2 represents the specification of the CTVs that will be investigated in the simulations. CTV-1 has higher operational capabilities than CTV-2, which results in higher daily charter rate payments than CTV-2. Additionally, higher fuel consumption rate for CTV-1 influences the total fuel cost.

The offshore wind turbine is considered to be structured from 12 different sub-components which form a series turbine system (Table 3). The time required and the repair costs of these components are adapted from the studies done by Faulstich, et al. [44] and Poore and Walford [45].

Table 2. CTV specifications

\begin{tabular}{lcc}
\hline Specification & CTV-1 & CTV-2 \\
\hline Vessel Type & Catamaran & Catamaran \\
Length (m) & 27 & 19.5 \\
Demi-hull Breadth (m) & 2.95 & 2.52 \\
Draught (m) & 1.75 & 1.5 \\
Displacement (tons) & 135 & 65 \\
Speed (knots) & 26 & 23 \\
Installed Power (kW) & 1440 & 1006 \\
Op. Wave Height (m) & $1.7-1.6-1.5$ & $1.45-1.35-1.25$ \\
Op. Wind Speed (m/s) & 25 & 25 \\
Fuel Cons. (1/h) & 384 & 200 \\
Charter rate (£/day) & 3500 & 1750 \\
Technician capacity & 12 & 12 \\
\hline
\end{tabular}

Table 3. Turbine components

\begin{tabular}{rlcc}
\hline No & Component name & Repair Time (days) & Repair Cost (£) \\
\hline 1 & Electrical system & 0.17 & 555 \\
2 & Electronic control & 0.15 & 4121 \\
3 & Sensors & 0.16 & 1200 \\
4 & Hydraulic System & 0.18 & 1276 \\
5 & Yaw System & 0.16 & 551 \\
6 & Rotor Hub & 0.18 & 4288 \\
7 & Mechanical Brake & 0.16 & 2405 \\
8 & Rotor Blades & 0.18 & 18174 \\
9 & Gearbox & 0.17 & 3243 \\
10 & Generator & 0.15 & 11189 \\
11 & Support \& Housing & 0.14 & 11189 \\
12 & Drive Train & 0.17 & 13862 \\
\hline
\end{tabular}


Due to the fact that CTV operations will be simulated, it is important to identify the time dependent rates for minor wind turbine failures. In this respect, Faulstich, et al. [44] investigated the failure rates depending on the severity of the failures and presented constant rates for minor failures. In order to demonstrate the development and change of failure rates throughout simulation period, all the failure rates are modified to individual bathtub curve distributions which represent the infant, random, and wear-out failures through 2 parameter Weibull distributions.

Table 4 shows the scale $\lambda$ and shape $k$ parameters associated with each component and the period of lifetime. At this stage, it is important to highlight that the knowledge and experience related to reliability figures and the failure rates of offshore wind turbines are very limited, therefore, it should be possible to utilise more accurate offshore wind failure rates in the future. The bathtub curves are generated by plotting the rate of early failures when first introduced, the rate of random failures with constant failure rate during the components useful life, and finally the rate of wear-out failures as the product exceeds its design lifetime (Figure A.1).

Table 5 shows the additional parameters which have to be defined before running the simulations. As explained in the methodology section the number of technicians allocated to a failed turbine depends on the time required for that repair and available weather window on the repair day. Therefore, 2 technicians will be allocated if the weather window is sufficient enough to be completed the repair in a single shift. Otherwise, 4 technicians will be allocated to complete the repairs quicker.

Table 4. Weibull distribution parameters

\begin{tabular}{rcccccc}
\hline No & Infant $\boldsymbol{\lambda}$ & Infant k & Random $\boldsymbol{\lambda}$ & Random k & Wear $\boldsymbol{\lambda}$ & Wear k \\
\hline 1 & 0.2 & 0.7 & 6 & 1 & 13 & 5 \\
2 & 0.37 & 0.75 & 10 & 1 & 13 & 4 \\
3 & 0.37 & 0 & 1.25 & 1 & 13 & 0 \\
4 & 0.4 & 0.43 & 5 & 1 & 13 & 4 \\
5 & 0.9 & 0.41 & 4 & 1 & 16 & 4 \\
6 & 0.9 & 0.41 & 4.8 & 1 & 16 & 4 \\
7 & 0.5 & 0.29 & 4.8 & 1 & 16 & 4 \\
8 & 0.5 & 0.29 & 8 & 1 & 16 & 4 \\
9 & 0.7 & 0.2 & 20 & 1 & 15 & 3.5 \\
10 & 0.8 & 0.3 & 20 & 1 & 16.5 & 5 \\
11 & 0.8 & 0.5 & 30 & 1 & 19.8 & 12 \\
12 & 0.3 & 0.15 & 50 & 1 & 20 & 11 \\
\hline
\end{tabular}

Table 5. Additional parameters

\begin{tabular}{lc}
\hline Parameter & Value \\
\hline Electricity price $£ / \mathrm{kWh}$ & 0.1575 \\
Turbine capacity (kW) & 5000 \\
Number of turbines & 100 \\
Distance to shore (nmiles) & 20 \\
Observation point from sea level (m) & 10 \\
Hub level from sea level (m) & 100 \\
Wind shear component & 0.1 \\
Regular number of technicians & 2 \\
Maximum number of technicians & 4 \\
Maximum turbine visits by single CTV & 6 \\
Scheduled maintenance (manh/year) & 80 \\
Annual salary of a technician (£) & 50000 \\
Minimum working limit (h) & 2 \\
Inflation rate (\%/year) & 5 \\
Fuel cost (£/lt) & 0.9 \\
Shift-start/ Shift-finish & 8 a.m./8 p.m. \\
\hline
\end{tabular}


For the cost calculations 5\% inflation rate is considered, therefore electricity price, staff salaries, CTV charter payments, and fuel cost will be increased each year within the simulations.

\section{RESULTS}

In this case study, the different CTV fleet compositions for an offshore wind farm which consists of $100 \times 5 \mathrm{MW}$ are examined. Figures A.3-A.6 present the mean of generated wind speed at $10 \mathrm{~m}$ height, wind speed at hub height, wave period, and wave height datasets which are used in the simulations. The straight lines present the mean values of the original datasets. Through the climate dataset generation from original dataset, the estimated variations are achieved in the simulations considering the general characteristics of the original observations.

In the methodology section, the failure rate update logic was introduced. The repair of a failure leads to a reset for the failure rate of the failed component, and therefore an update in the system failure rate. Figure A.2 demonstrates the failure rate development of 1 sample turbine and its components within 1 simulation. Due the variations in the failure timings, all the turbines have different failure development curves within simulations. The sharp increments denote that there was a failure on that component, the repair was completed and therefore the failure rate of the failed component was reset. It can be seen that the electrical system failures occurred more frequently than others. On the other hand, drive train which has the lowest failure rate failed only 1 time within 20 years. With regard to sensors, it was assumed that this component has a constant failure rate; therefore it not possible to identify the number of failures from Figure A.2.

Figures 4-11 present the core outputs of this study. The values on the radial axes show the composition of fleet in the polar charts. The first value symbolises the number of CTV-1s in the fleet, and the second value symbolises the number of CTV-2s. The values on vertical axes show the calculated parameters associated with each fleet composition.

With regard to the total fuel cost, it can be recognised that the total fuel cost is not increasing proportional to the fleet size, but there are significant increases on the total fuel cost when the fleets are composed of only CTV-1 (Figure 4). Due to the fact that the CTV with higher fuel consumption is only available in these particular fleet compositions, there is no cheaper alternative to CTV-1.

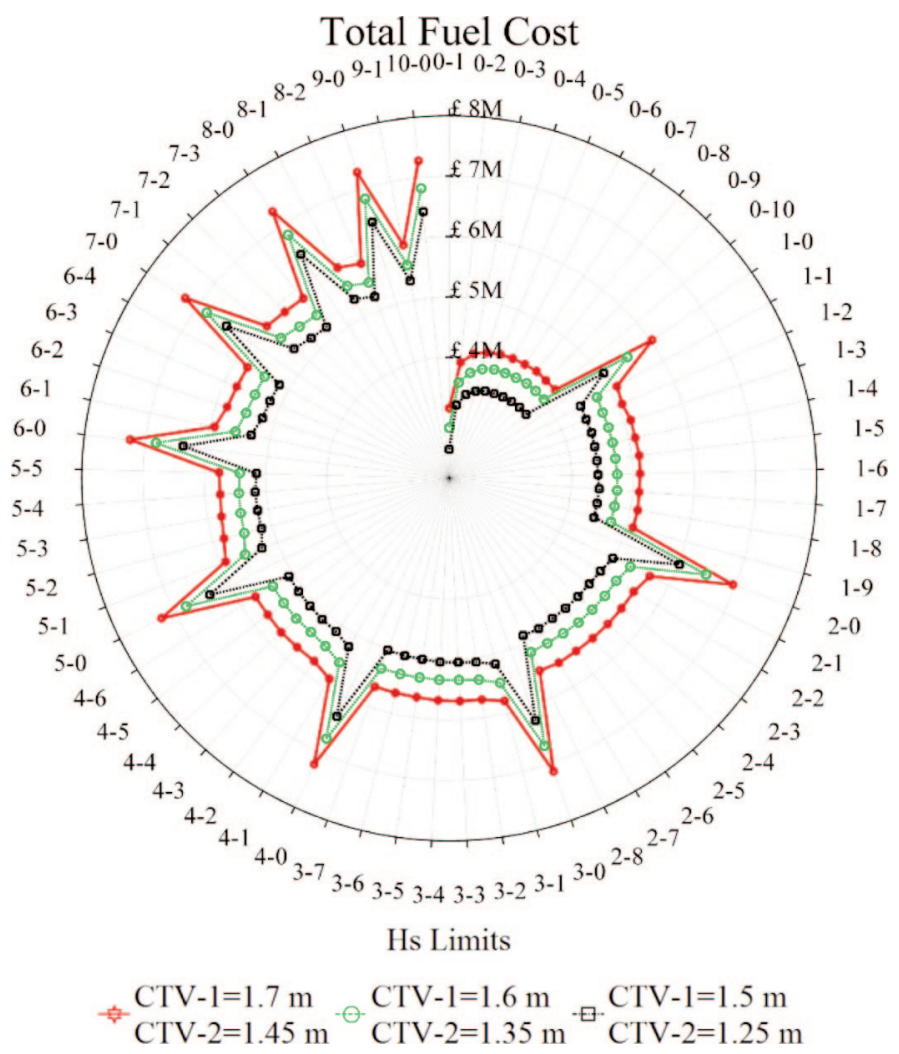

Figure 4. Total fuel cost for each fleet composition 
For other fleets, there is an alternative to CTV-1; therefore, the repair task can be completed by a CTV-2 which has a significantly lower fuel consumption. When different operational limitations are considered, higher operability increases the number of days that the wind farm is accessible; therefore the fleets with $1.7 \mathrm{~m}$ and $1.45 \mathrm{~m}$ operational wave height limits have better capability to perform the repairs which increases the number of visits done by CTVs. Therefore, the fleets with higher capability results in higher fuel cost during lifecycle of the project.

The total staff cost is directly proportional to the number of CTVs in the fleet composition; therefore when a new CTV is added to the composition regardless of its capabilities, the staff costs are increased (Figure 5). The total CTV charter cost is again very much dependent on the number of CTVs in the fleet composition, however, the daily charter rates of these vessels are also a significant element in the charter payments of the overall fleet (Figure 6). Due to the fact that the daily charter cost of CTV-1 is higher than CTV-2, the fleets, which have a higher number of CTV-1s in the composition, cause higher charter payment within a simulation period. The staff and CTVs are paid regardless of the fleet utilisation, therefore the graphs intersect for these cost attributes under different operational limitations.

The total Original Equipment Manufacturer (OEM) cost is dependent on the failure rates of the system and its components (Figure 7). However, the reaction time influences the number of hours that the components are in a functioning state. In this respect, the failures occur more frequently if the turbines are kept more in the functioning state. For instance, if a turbine is not repaired after the first failure for the entire simulation period, the OEM cost for that turbine will be 0 ; however that turbine will never function again. Therefore, the increase in the fleet size and the improvement in the operability increases the OEM costs.

The total O\&M cost comprises of the total fuel cost, the total CTV charter cost, the total staff cost, and the total OEM cost. In this case, CTV charter costs are the most dominant factor by $47.01 \%$ in the total O\&M cost distribution. Fuel cost, staff cost, and OEM costs contribute $1.36 \%$, $30.20 \%$, and $21.41 \%$, respectively.

Total power generation, availability and total revenue figures have similar outlines, because all these parameters are directly proportional to the number of hours that the wind turbines are in a functioning state (Figure 8-10). The fact that the higher number of CTVs brings flexibility to

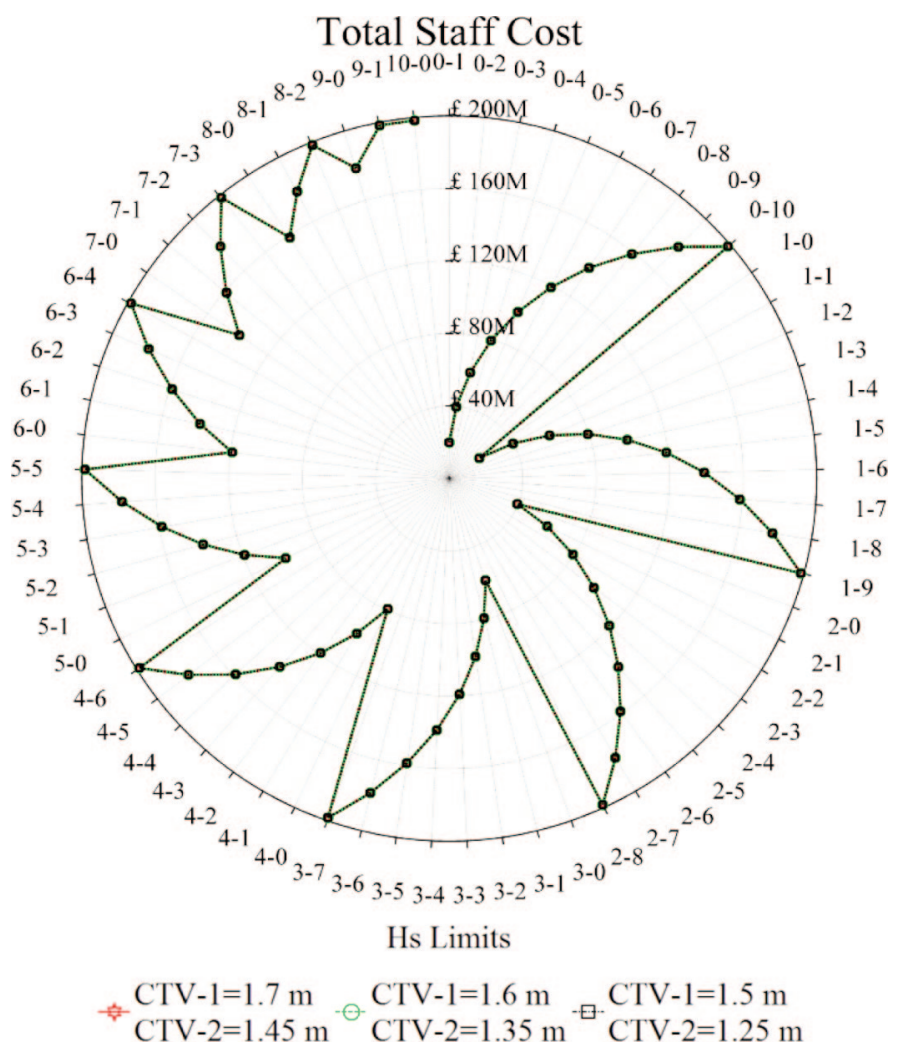

Figure 5. Total staff cost for each fleet composition 


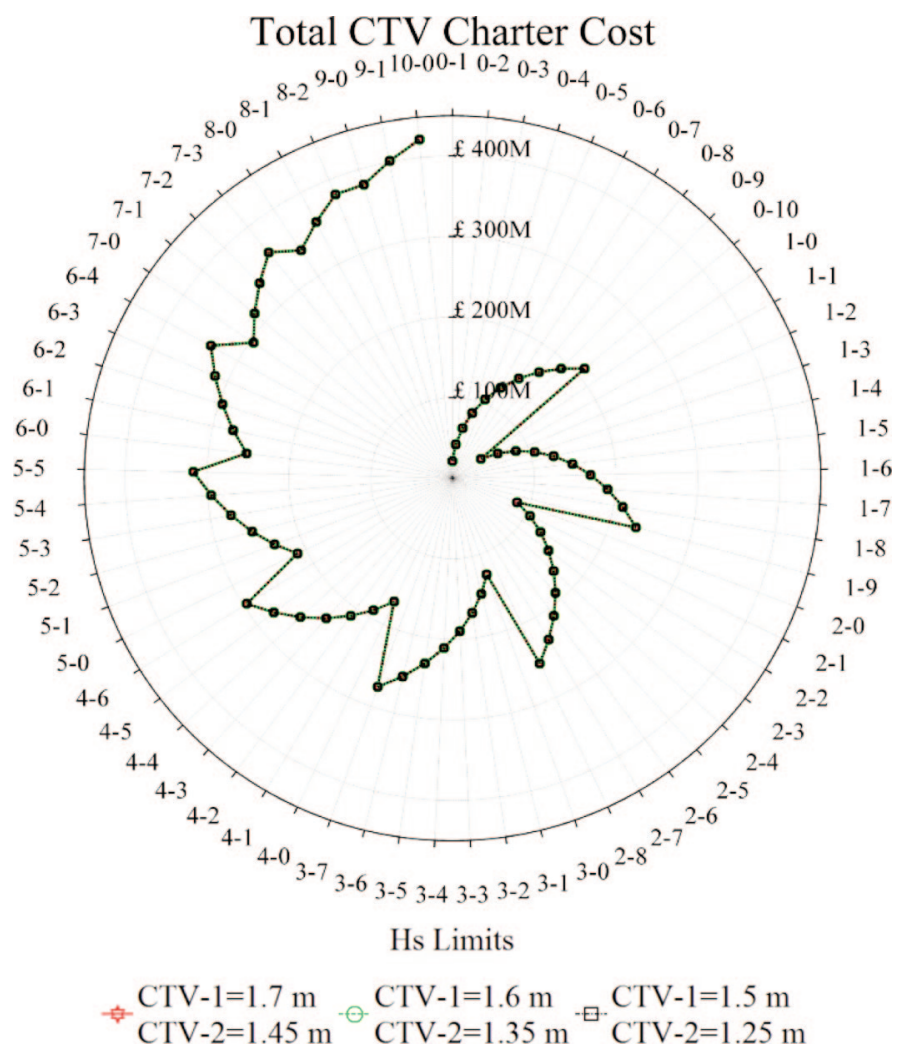

Figure 6. Total CTV charter cost for each fleet composition

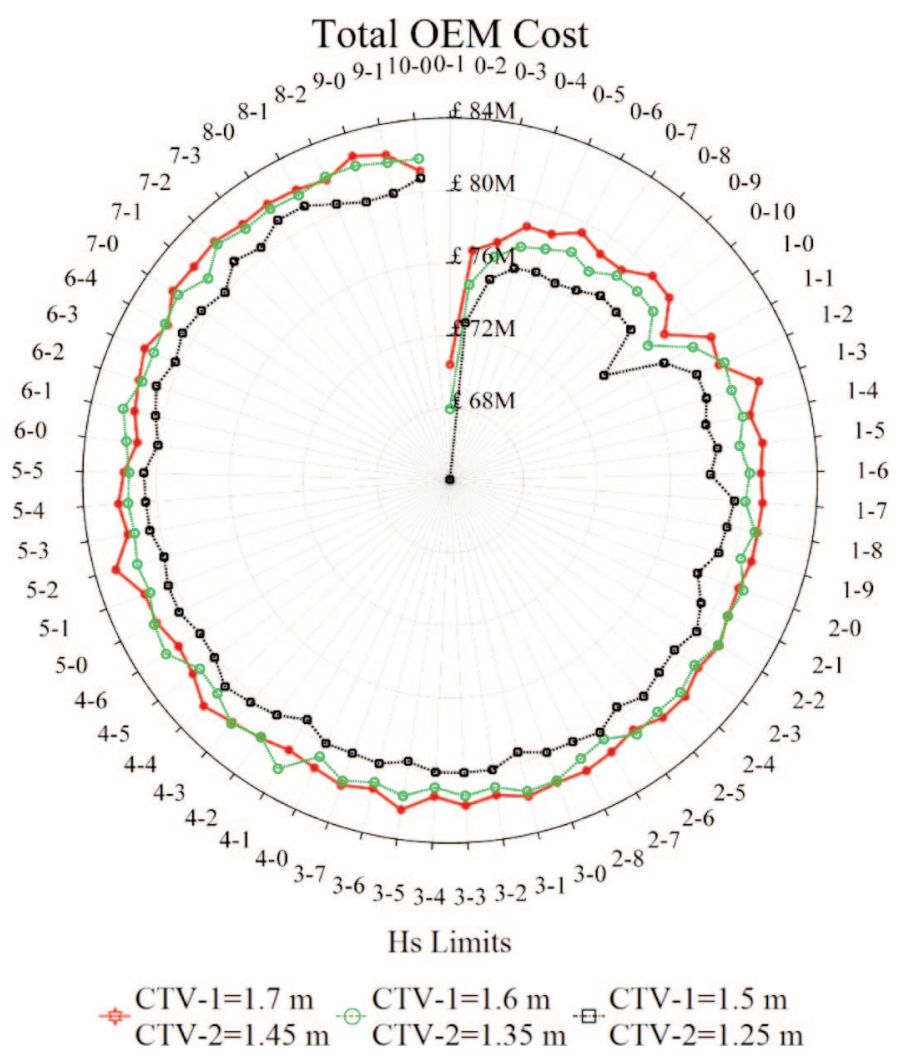

Figure 7. Total OEM cost for each fleet composition 


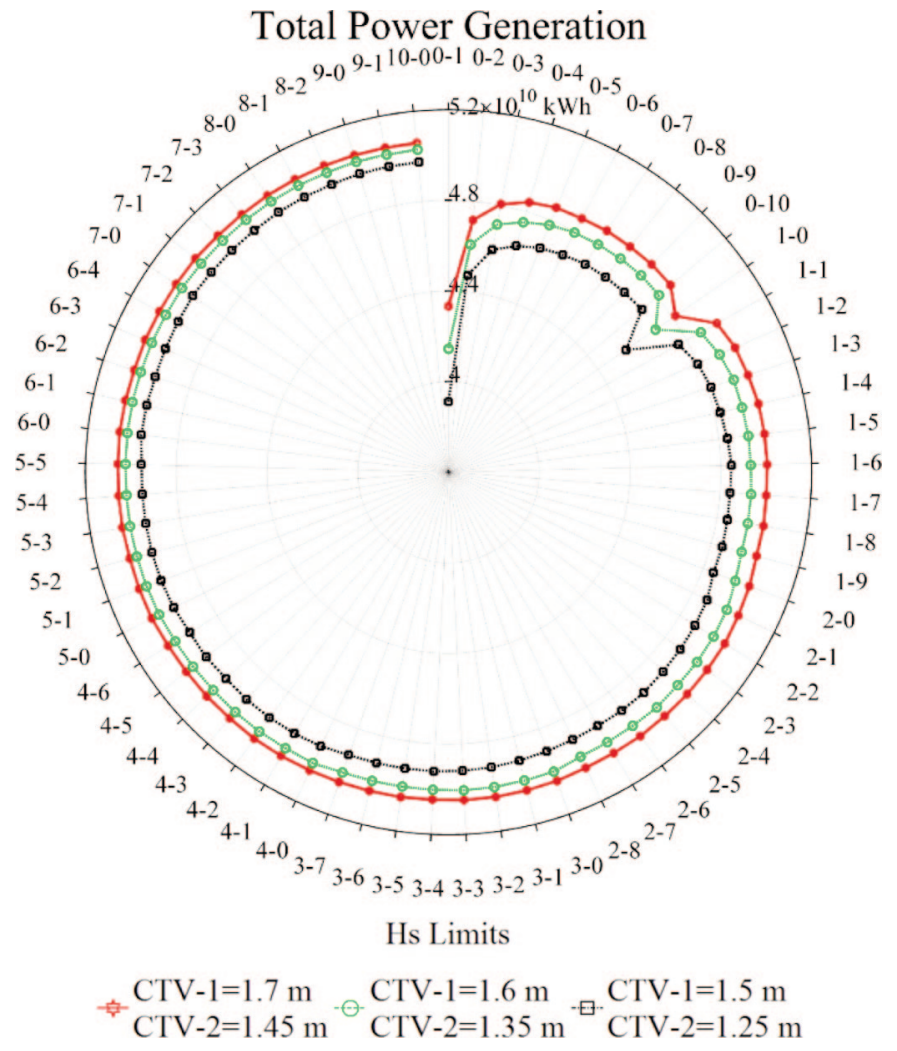

Figure 8. Total generated power for each fleet composition

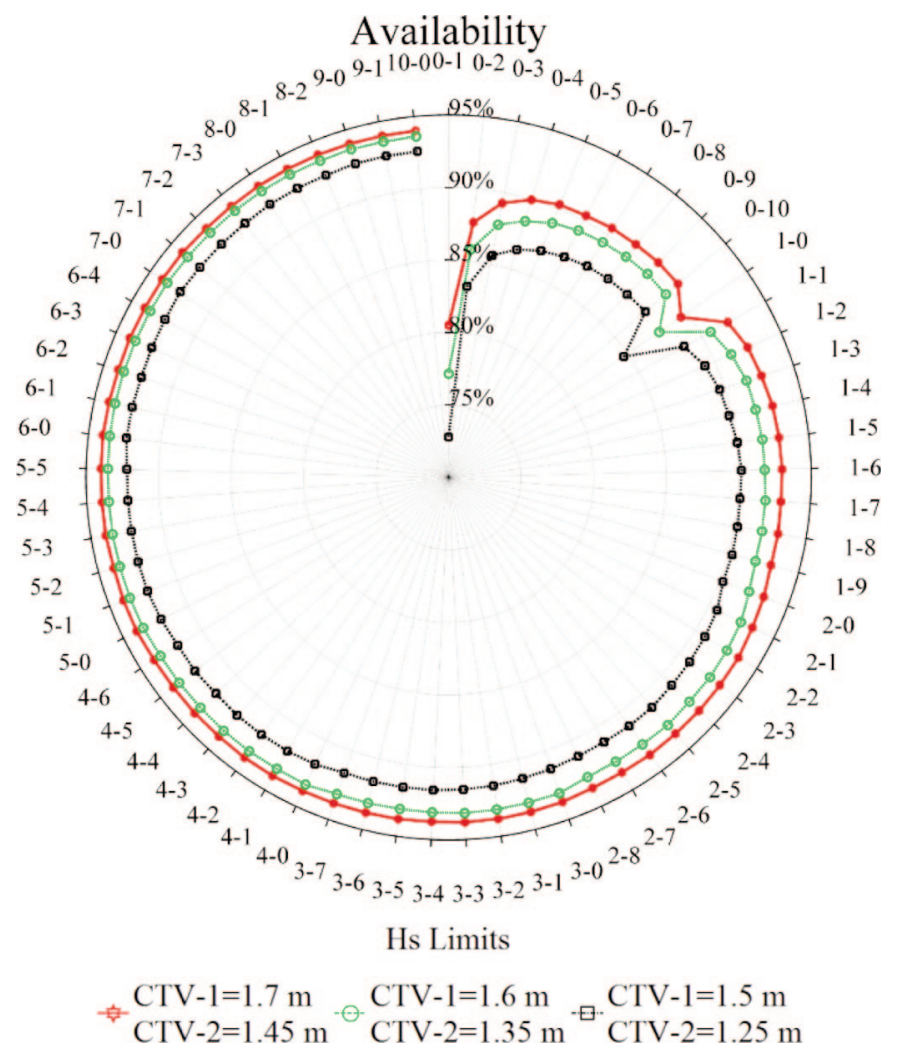

Figure 9. Availability for each fleet composition 


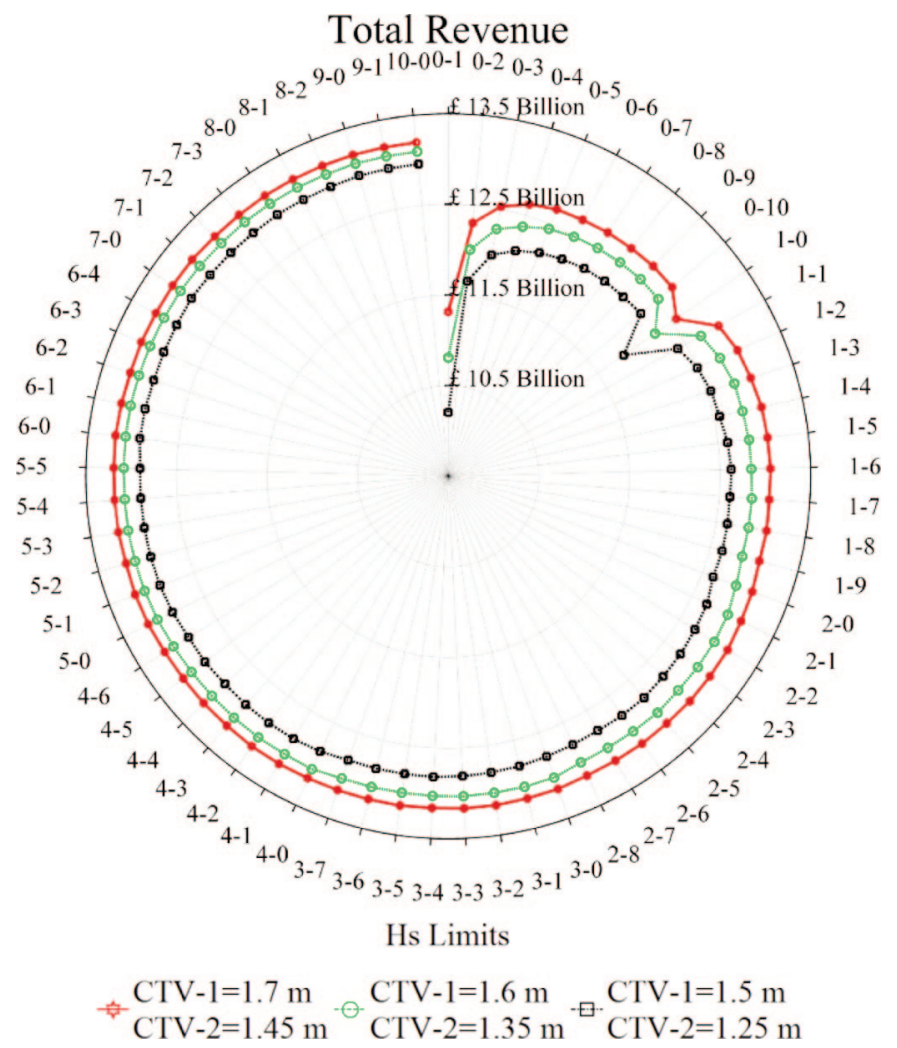

Figure 10. Total revenue for each fleet composition

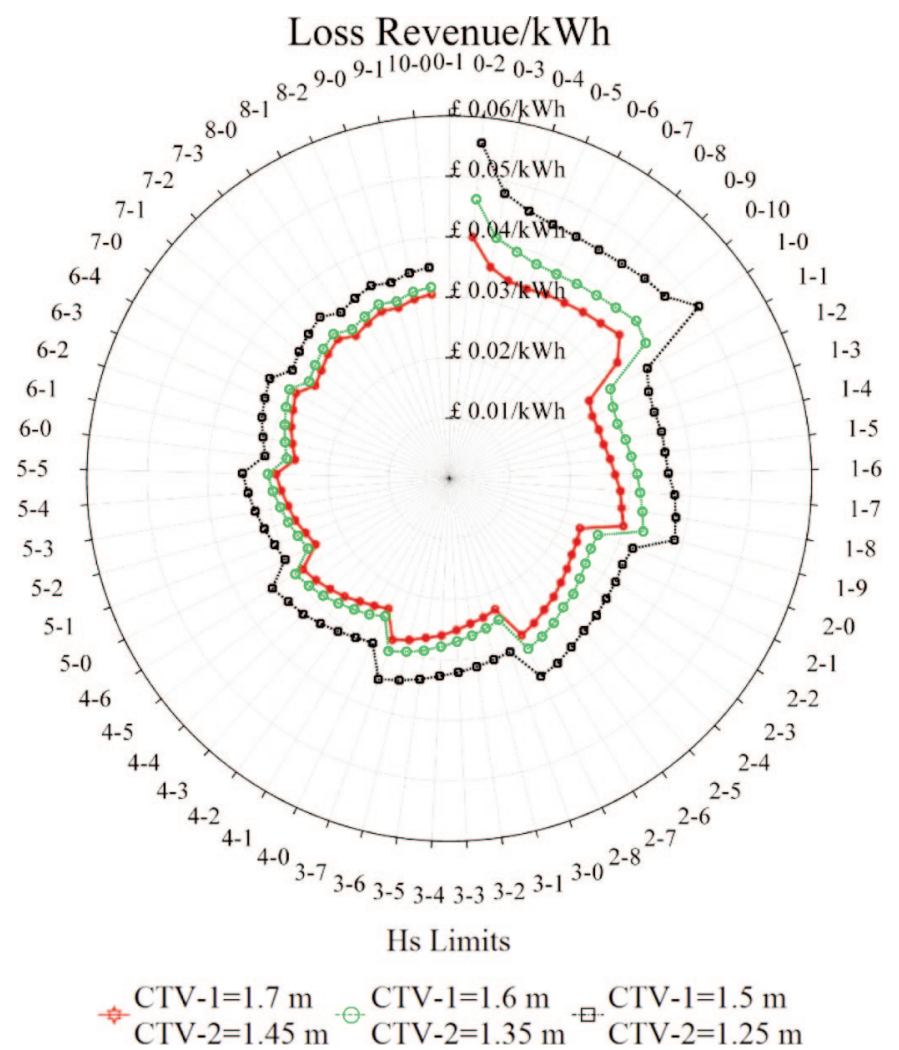

Figure II. Loss revenue/kWh for each fleet composition 
the O\&M activities; total power generation, availability which is a function of power generation and theoretical power generation, and total revenue which is a function of total power generation and electricity selling price have increasing trend proportional to the size of fleet. The improvement in the operability also increases the power generation, availability and total revenue of the projects.

The final decision can be made by assessing loss revenue/kWh values in Figure 11. In the loss revenue cost $/ \mathrm{kWh}$ calculation, all the cost and power production aspects are taken into account. These values include the power production improvement and the cost variation with the fleet size change. A significant decrease in loss of revenue can be noticed when a new CTV-1 joins the fleet; on the contrary when a new CTV-2 joins the fleet, the cost values increase gradually. When the best configurations are identified as in Table 6 and Table 7, the rankings show that CTV-2 is not as cost effective as CTV-1, despite CTV-1 being more expensive to charter. The CTVs with the lowest operational wave height limit require relatively larger fleet compositions. This is due to the fact that when a 5 MW turbine is taken into account, 1 day downtime costs $£ 10,000-£ 19,000$ revenue loss which is substantially higher compared to the maintenance costs. The influence of operability can be noticed when the rankings assessed in Table 7. When all the Hs categories are considered together, the best 10 fleet compositions have the highest operational capabilities. In addition, the improvements on the operability of the vessels leads to smaller technician teams and fleets which also decrease the economic risks.

Table 6. The best fleet configurations within each $\mathbf{H}_{s}$ limit category

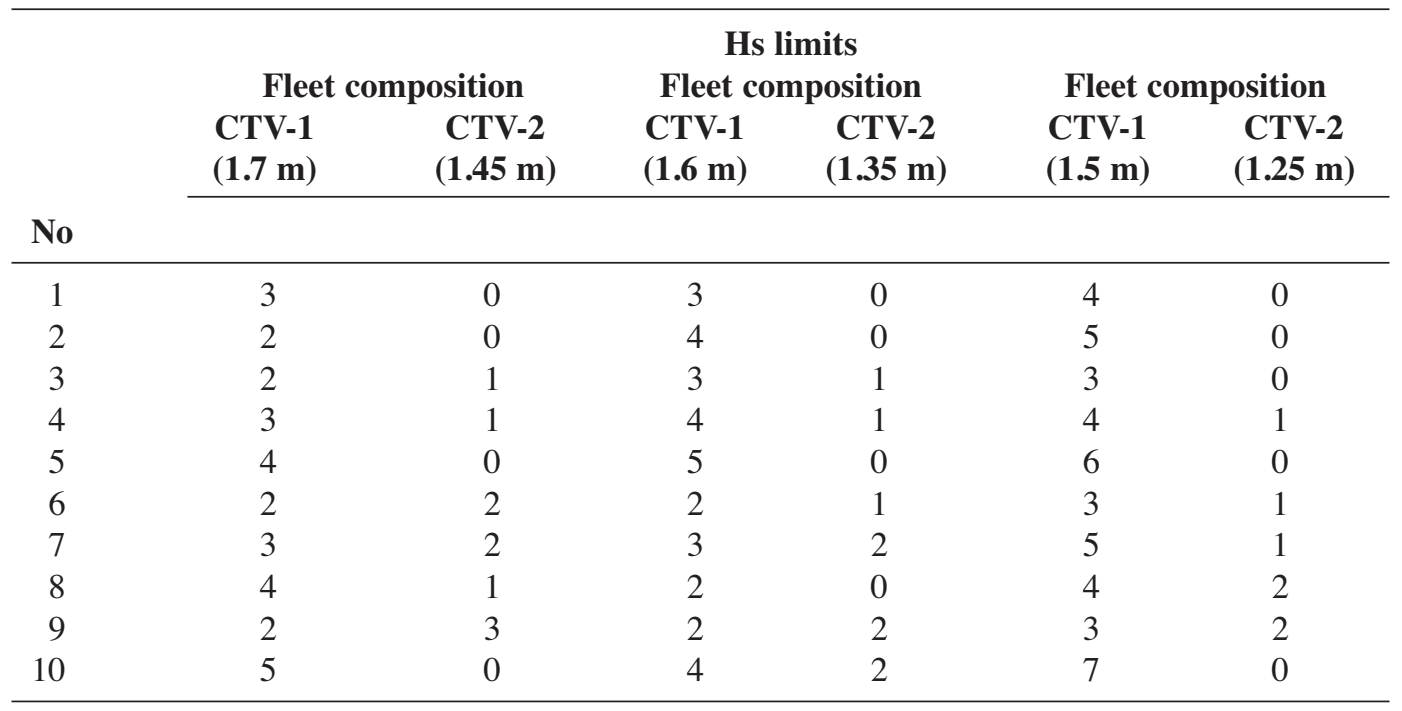

Table 7. The best fleet configurations within all categories

\begin{tabular}{ccccc}
\hline No & Hs limits & CTV-1 & CTV-2 & Loss revenue/kWh \\
\hline 1 & $1.7 \mathrm{~m}-1.45 \mathrm{~m}$ & 3 & 0 & $£ 0.0230$ \\
2 & $1.7 \mathrm{~m}-1.45 \mathrm{~m}$ & 2 & 0 & $£ 0.0231$ \\
3 & $1.7 \mathrm{~m}-1.45 \mathrm{~m}$ & 2 & 1 & $£ 0.0236$ \\
4 & $1.7 \mathrm{~m}-1.45 \mathrm{~m}$ & 3 & 1 & $£ 0.0237$ \\
5 & $1.7 \mathrm{~m}-1.45 \mathrm{~m}$ & 4 & 0 & $£ 0.0238$ \\
6 & $1.7 \mathrm{~m}-1.45 \mathrm{~m}$ & 2 & 2 & $£ 0.0239$ \\
7 & $1.7 \mathrm{~m}-1.45 \mathrm{~m}$ & 3 & 2 & $£ 0.0243$ \\
8 & $1.7 \mathrm{~m}-1.45 \mathrm{~m}$ & 4 & 1 & $£ 0.0244$ \\
9 & $1.7 \mathrm{~m}-1.45 \mathrm{~m}$ & 2 & 3 & $£ 0.0246$ \\
10 & $1.7 \mathrm{~m}-1.45 \mathrm{~m}$ & 5 & 0 & $£ 0.0247$ \\
\hline
\end{tabular}




\section{CONCLUDING REMARKS}

In this study, an extensive CTV fleet selection methodology is introduced for offshore wind farm O\&M activities towards optimum O\&M cost, minimum revenue loss, and maximum electricity generation. Climate parameters, failure characteristics of turbine components, the specification of crew transfer vessels and the composition of vessel fleet are simulated within the operational phase of an offshore wind farm. The results are demonstrated to support the decision making related to the maintenance and logistic strategy. The consequences of different decisions can be assessed and the CTV fleet, which brings financial and operational benefits, can be selected.

It is envisaged that a CTV with better capability brings great financial and operational advantages, even though that CTV has higher daily operating expenditures (OPEX) cost. Increasing the size of the CTV fleet does not always bring an economic advantage due to the fact that the cost increase cannot be compensated by the production increase if the CTV fleet becomes larger than the optimum level. The capability and operational limitations of the CTVs are also important attributes which significantly influence the fleet size. Therefore, offshore wind farm operators should consider new generation CTVs, which have higher operational capabilities, while organising their O\&M fleets.

\section{ACKNOWLEDGEMENTS}

Results were obtained using the EPSRC funded ARCHIE-WeSt High Performance Computer (www.archie-west.ac.uk). EPSRC grant no. EP/K000586/1.

\section{REFERENCES}

[1] WindPower Offshore, Global Offshore-Special Report, 2012, London, UK, 1-32.

[2] Fingersh, L., Hand, M., and Laxson, A., Wind Turbine Design Cost and Scaling Model, 2006, National Renewable Energy Laboratory.

[3] Junginger, M., Faaij, A., and Turkenburg, W.C., Cost reduction prospects for the offshore wind energy sector, Wind Engineering, 2004, 28 (1), 97-118.

[4] Krohn, S., Morthorst, P.-E., and Awerbuch, S., The Economics of Wind Energy, 2009, EWEA, Brussels.

[5] Morgan, C., Scott, N.C., and Snodin, H.M., Economies of Scale, Engineering Resource and Load Factors, 2003, London, UK.

[6] Gellatly, B., Operations \& Maintenance Special Report, 2013, WindPower Offshore, London, UK.

[7] WindPower Offshore, Vessels and Access, Special Report, 2013, London, UK.

[8] Evans, T., Proven Operations and Maintenance Strategy, Technology and Equipment Demanded by Wind Operators, Wind Energy Update, 2010.

[9] Andrawus, J.A., Watson, J., Kishk, M., and Gordon, H., Optimisation of Wind Turbine Inspection Intervals, Wind Engineering, 2008, 32 (5), 477-490.

[10] Nielsen, J.J. and Sorensen, J.D., On risk-based operation and maintenance of offshore wind turbine components, Reliability Engineering \& System Safety, 2011, 96 (1), 218-229.

[11] Yan-ru, W. and Hong-Shan, Z., Optimization maintenance of wind turbines using Markov decision processes, International Conference on Power System Technology (POWERCON), 2010, 1-6.

[12] Eunshin, B., Ntaimo, L., and Yu, D., Optimal Maintenance Strategies for Wind Turbine Systems Under Stochastic Weather Conditions, IEEE Transactions on Reliability, 2010, 59 (2), 393-404.

[13] Lazakis, I., Turan, O., and Rosendahl, T., Modelling of vessel and equipment cost for the maintenance activities of an offshore tidal energy array, Proceedings of the PRADS2013, Changwon City, Korea, 2013.

[14] Lazakis, I., Turan, O., and Rosendahl, T., Risk assessment for the installation and maintenance activities of a low-speed tidal energy converter, Marine \& Offshore Renewable Energy Conference, London, UK, 2012. 
[15] Wiggelinkhuizen, E., Verbruggen, T., Braam, H., Rademakers, L., Xiang, J., and Watson, S., Assessment of condition monitoring techniques for offshore wind farms, Journal of solar energy engineering, 2008, 130 (3), 030301.1-031020.12.

[16] Hameed, Z., Ahn, S.H., and Cho, Y.M., Practical aspects of a condition monitoring system for a wind turbine with emphasis on its design, system architecture, testing and installation, Renewable Energy, 2010, 35 (5), 879-894.

[17] Verbruggen, T.W., Wind Turbine Operation \& Maintenance based on Condition Monitoring, $2003,39$.

[18] Ribrant, J. and Bertling, L.M., Survey of Failures in Wind Power Systems With Focus on Swedish Wind Power Plants During 1997-2005, IEEE Transactions on Energy Conversion, 2007, 22 (1), 167-173.

[19] Smolders, K., Long, H., Feng, Y., and Tavner, P., Reliability analysis and prediction of wind turbine gearboxes, European Wind Energy Conference, 2010.

[20] Haitao, G., Xianhui, Y., Jianping, X., and Watson, S., Wind turbine availability analysis based on statistical data, International Conference on Sustainable Power Generation and Supply, 2009, 1-6.

[21] Tavner, P., Offshore Wind Turbines: Reliability, availability and maintenance, The Institution of Engineering and Technology, London, UK, 2012.

[22] Arwade, S.R., Lackner, M.A., and Grigoriu, M.D., Probabilistic models for wind turbine and wind farm performance, Transactions of the ASME-N-Journal of Solar Energy Engineering, 2011, 133 (4), 041006.

[23] Arifujjaman, M., Iqbal, M.T., and Quaicoe, J.E., A comparative study of the reliability of the power electronics in grid connected small wind turbine systems, Canadian Conference on Electrical and Computer Engineerings, 2009, 394-397.

[24] Underbrink, A., Hanson, J., Osterholt, A., and Zimmermann, W., Probabilistic Reliability Calculations for the Grid Connection of an Offshore Wind Farm, International Conference on Probabilistic Methods Applied to Power Systems, 2006, 1-5.

[25] Bertling, L., Allan, R., and Eriksson, R., A reliability-centered asset maintenance method for assessing the impact of maintenance in power distribution systems, IEEE Transactions on Power Systems, 2005, 20 (1), 75-82.

[26] Brown, R.E. and Taylor, T.M., Modeling the impact of substations on distribution reliability, IEEE Power Engineering Society 1999 Winter Meeting, 1999, 349-354.

[27] Spinato, F., Tavner, P.J., van Bussel, G.J.W., and Koutoulakos, E., Reliability of wind turbine subassemblies, IET Renewable Power Generation, 2009, 3 (4), 387-401.

[28] Faulstich, S., Hahn, B., Lyding, P., and Tavner, P., Reliability of offshore turbinesidentifying risks by onshore experience, Proc. European Offshore Wind, 2009, 14-16.

[29] Utne, I.B., Maintenance strategies for deep-sea offshore wind turbines, Journal of Quality in Maintenance Engineering, 2010, 16 (4), 367-381.

[30] El-Thalji, I., On the operation and maintenance practices of wind power asset: A status review and observations, Journal of Quality in Maintenance Engineering, 2012, 18 (3), 232-266.

[31] Gualtieri, G. and Secci, S., Methods to extrapolate wind resource to the turbine hub height based on power law: A 1-h wind speed vs. Weibull distribution extrapolation comparison, Renewable Energy, 2012, 43 (0), 183-200.

[32] Lackner, M.A., Rogers, A.L., Manwell, J.F., and McGowan, J.G., A new method for improved hub height mean wind speed estimates using short-term hub height data, Renewable Energy, 2010, 35 (10), 2340-2347.

[33] Gryning, S.E., Batchvarova, E., Brummer, B., Jorgensen, H., and Larsen, S., On the extension of the wind profile over homogeneous terrain beyond the surface boundary layer, 
Boundary-Layer Meteorology, 2007, 124 (2), 251-268.

[34] Firtın, E., Güler, Ö., and Akdağ, S.A., Investigation of wind shear coefficients and their effect on electrical energy generation, Applied Energy, 2011, 88 (11), 4097-4105.

[35] Manwell, J.F., McGowan, J.G., and Rogers, A.L., Wind energy explained : theory, design and application, 2nd edn., John Wiley, Chichester, UK, 2009.

[36] Bechrakis, Bechrakis, D.A., Sparis, and Sparis, P.D., Simulation of the Wind Speed at Different Heights Using Artificial Neural Networks, Wind Engineering, 2000, 24 (2), 127-136.

[37] Burton, T., Jenkins, N., Sharpe, D., and Bossanyi, E., Wind Energy Handbook, 2nd edn., Wiley, Oxford, UK, 2011.

[38] Helm, G., Systematische Propulsions-Untersuchungen von Kleinschiffen (Systematic investigations propulsion of small ships), Forschungszentrum des Deutschen Schiffbaus (Research of the German Shipbuilding), Hamburg, Germany, 1980.

[39] Moody, R., Preliminary Power Prediction During Early Design Stages Of A Ship, PhD, Cape Technikon, 1996.

[40] MAN Diesel \& Turbo, Basic Principles of Ship Propulsion, 2011, Copenhagen, Denmark.

[41] Jinkine, V. and Ferdinande, V., A method for predicting the added resistance of fast cargo ships in head waves, International Ship Building Progress, 1973, 21 (238).

[42] Berlekom, W.B.v., Tragardh, P., and Dellhag, A., Large tankers - Wind coefficients and speed loss due to wind and sea, Royal Institution of Naval Architects, 1974.

[43] Berlekom, W.B.v., Wind Forces on Modern Ship Forms - Effects on Performance, Transactions of the North East Institute of Engineers and Shipbuilders, 1981, 97 (4).

[44] Faulstich, S., Hahn, B., and Tavner, P.J., Wind turbine downtime and its importance for offshore deployment, Wind Energy, 2011, 14 (3), 327-37.

[45] Poore, R. and Walford, C., Development of an Operations and Maintenance Cost Model to
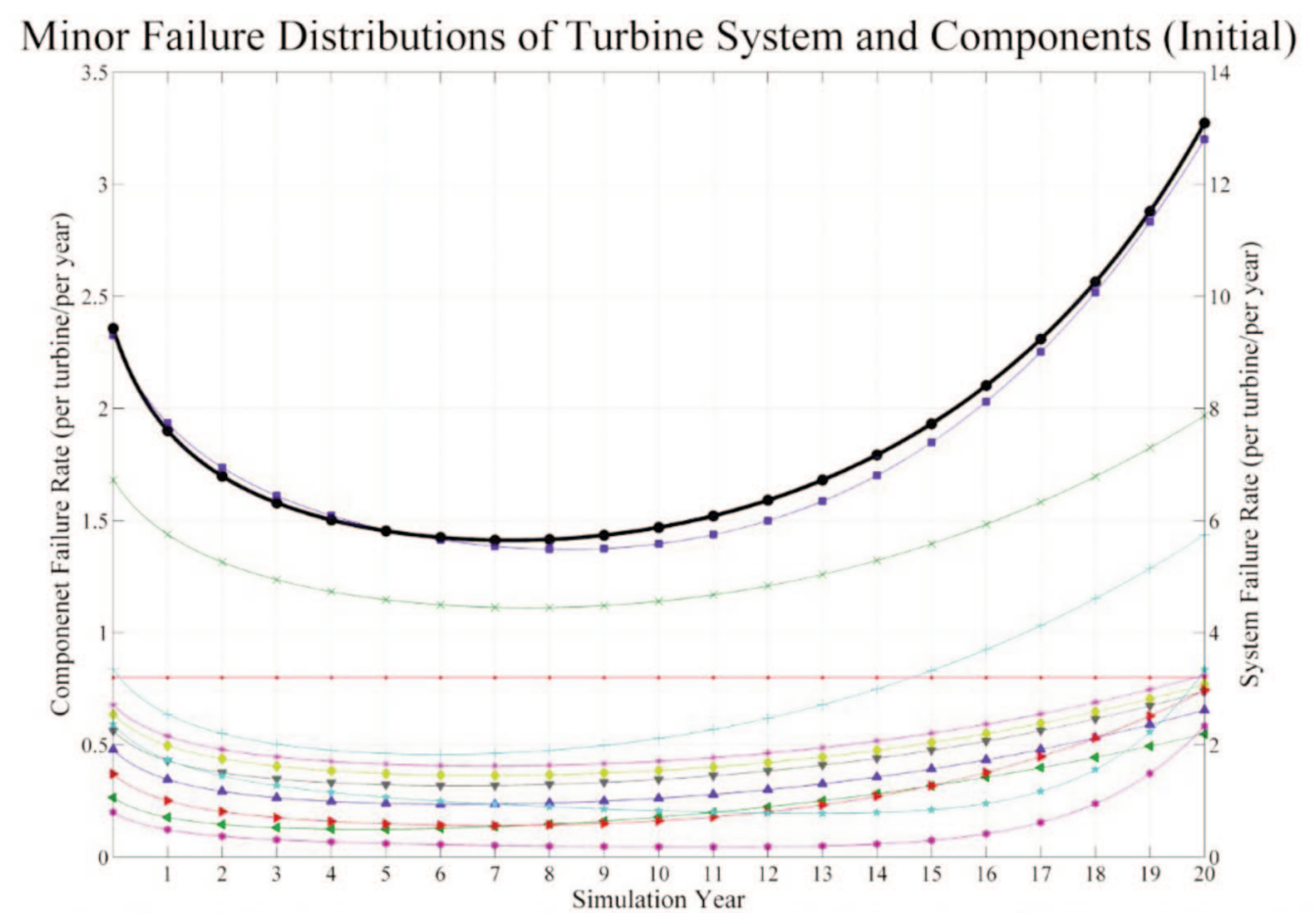

- Wind Turbine System -- Electrical system - Electronic control $\rightarrow$ Sensors $\rightarrow$ Hydraulic System $\rightarrow$ Yaw System $\rightarrow$ Rotor Hub

$$
\rightarrow \text { Mechanical Brake } \rightarrow \text { Rotor Blades } \rightarrow \text { Gearbox } \rightarrow \text { Generator } \rightarrow \text { Support \& Housing } \rightarrow \text { Drive Train }
$$

Figure A.I: Updated time dependent failure rates for offshore wind turbine system and components 
Minor Failure Distributions of Turbine System and Components (Updated)

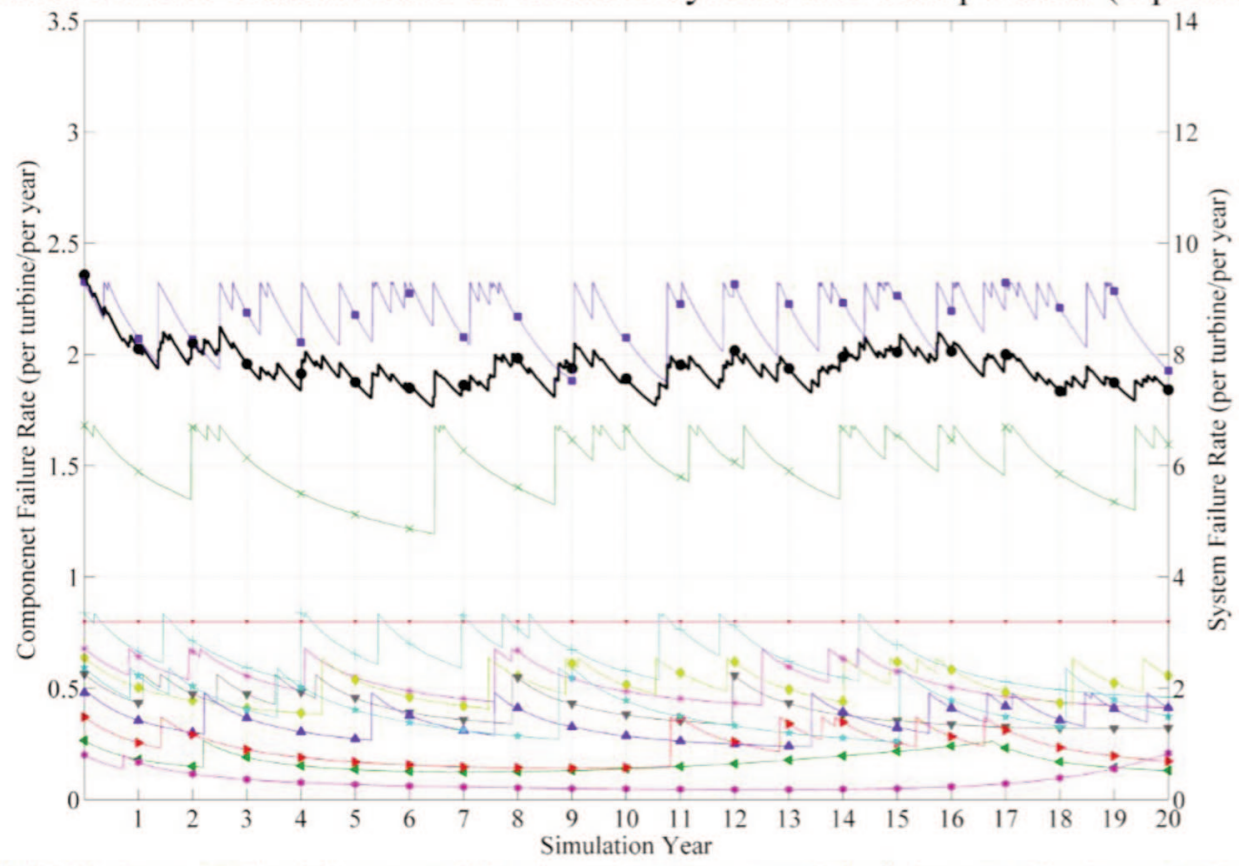

- Wind Turbine System - Electrical system - Electronic control $\rightarrow$ Sensors $\longrightarrow$ Hydraulic System $\rightarrow$ Yaw System $\rightarrow$ Rotor Hub

$\rightarrow$ Mechanical Brake $\rightarrow$ Rotor Blades $\rightarrow$ Gearbox $\rightarrow$ Generator $\rightarrow$ Support \& Housing $\rightarrow$ Drive Train

Figure A.2. Updated time dependent failure rates for offshore wind turbine system and components

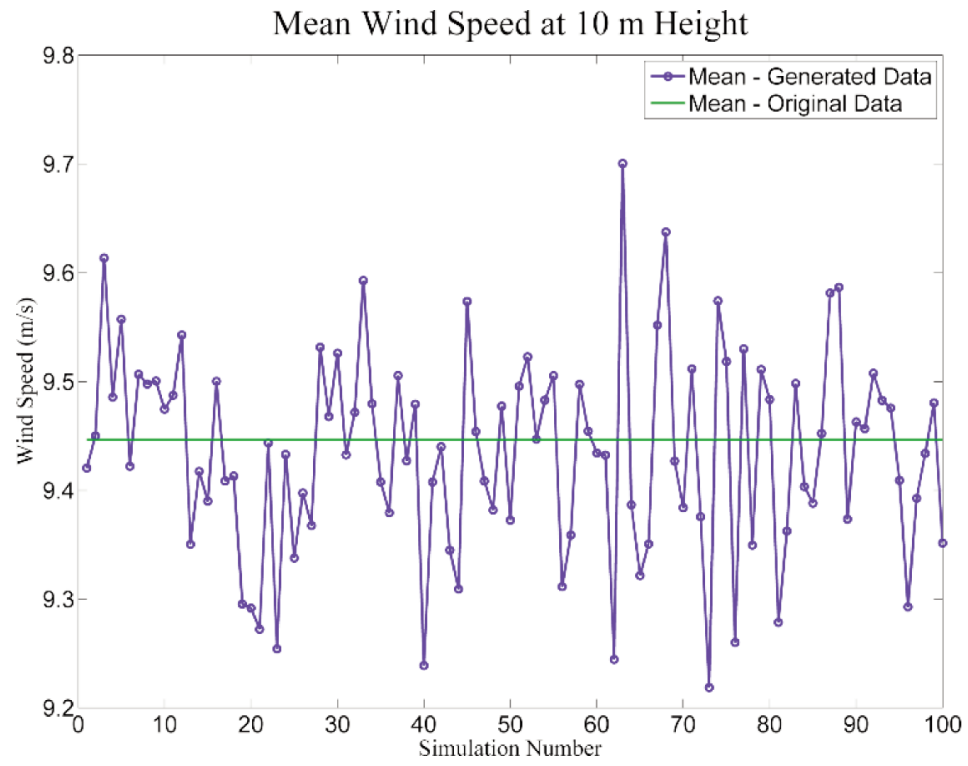

Figure A.3. Mean wind speed at $10 \mathrm{~m}$ height for original and generated datasets 


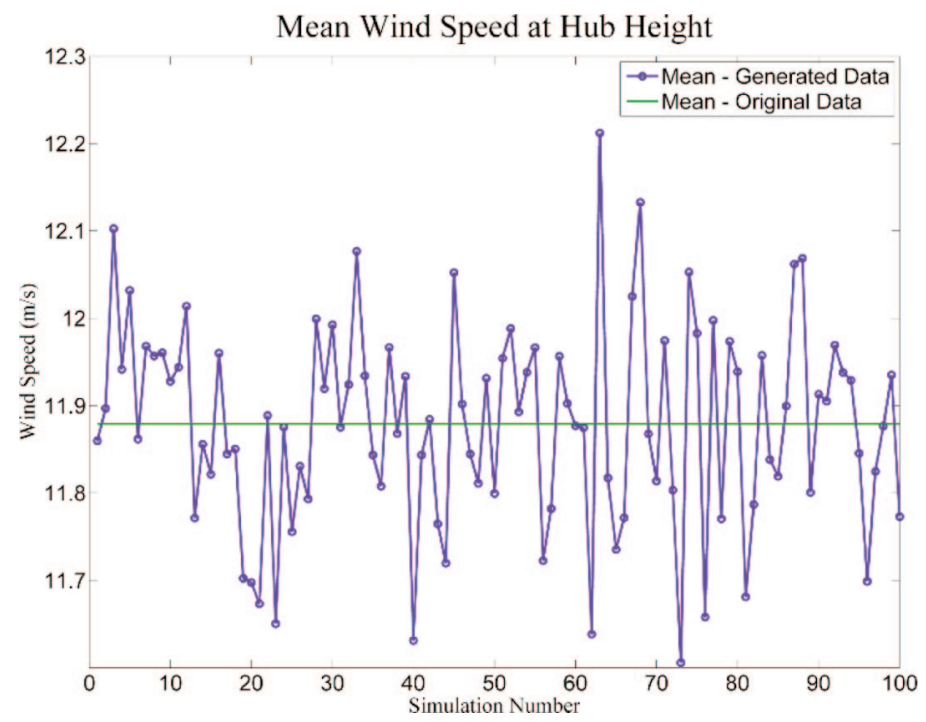

Figure A.4. Mean wind speed at hub height for original and generated datasets

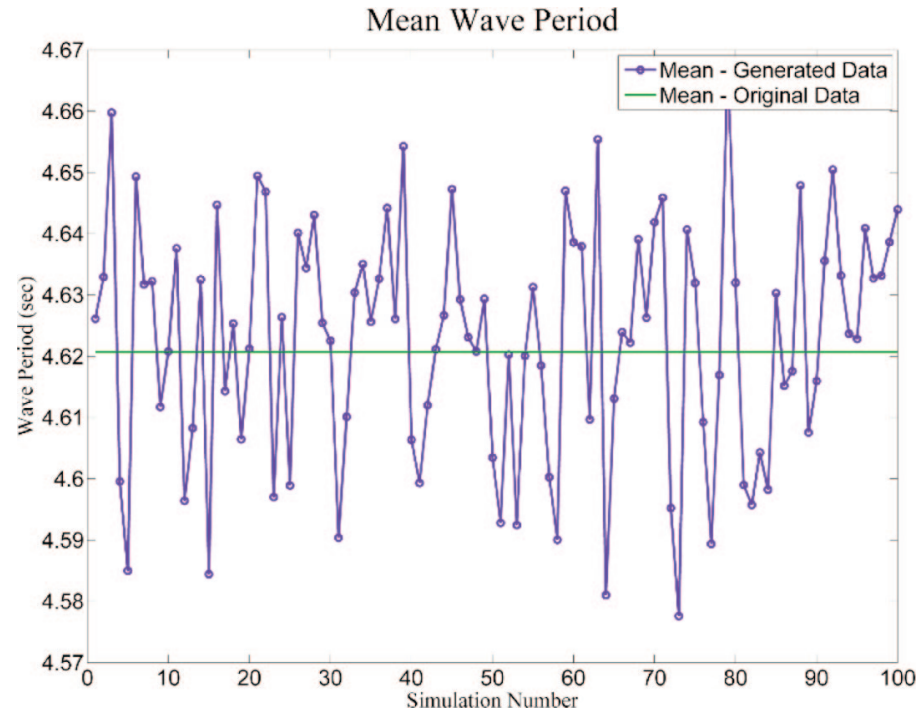

Figure A.5. Mean wave period for original and generated datasets

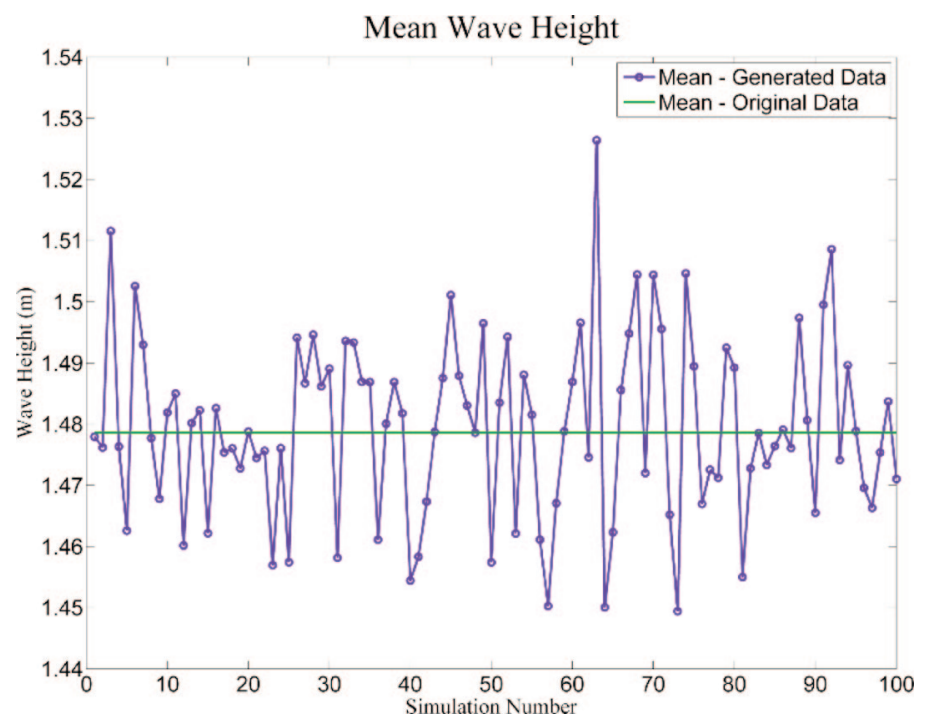

Figure A.6. Mean wave height for original and generated datasets 